\title{
PROSES UNTUK MEMPEROLEH HAK PATEN DAN SANKSI MELANGGAR PATEN MILIK ORANG LAIN
}

\section{RUDIYANTO \\ 15500068}

Fakultas Komputer, 448757187

Rudiyanto.student@umitra.ac.id

\begin{abstract}
Gisting Hotel yang terletak di Jl. Raya Gisting Bawah Blok.1 Tanggamus merupakan salah satu hotel yang memiliki fasilitas hotel pada umumnya dan berbagai macam hiburan yang mampu membuat para tamu nyaman dengan pemandangan menarik yang berhadapan langsung dengan Gunung Tanggamus.

Berkaitan dengan sistem penerimaan dan pengeluaran kas yang ada pada Gisting Hotel, pihak perusahaan mengupayakan sistem yang handal dan mampu menyajikan sistem penerimaan dan pengeluaran kas, “ isi abstrak ewakili isi pembahasan ( Introduction) dan kesimpulan ( conclusion) " terjadinya perubahan data yang dilakukan oleh karyawan sementara transaksi tersebut telah dilaporkan sehingga terjadinya perbedaan data mengakibatkan kerugian pihak perusahaan.

Hal tersebut dapat terjadi karena belum terintegrasinya antara bagian keuangan dan administrasi sehingga penyajian laporan yang dibuat menjadi tidak sama. Untuk itu perlunya usulan sistem yang berbasis jaringan untuk mendukung pengolahan data penerimaan dan pengeluaran kas sehingga penyajian laporan dapat dilakukan secara terstruktur.
\end{abstract}

Kata Kunci : Penerimaan dan Pengeluaran Kas. 


\section{A. INTRODUCTION}

Materi Ke 3 Membahas Tentang Paten, Inventor, Pemegang Paten, Apa Yang Harus Di Hindari Dalam Pengajuan Hak Paten Dan Pengungkapan Pada Sebuah Penemuan

\section{A. PATEN}

Paten adalah perlindungan HKI bagi karya intelektual yang bersifat teknologi, atau dikenal juga dengan istilah invensi, dan mengandung

pemecahan/solusi teknis terhadap masalah yang terdapat pada teknologi yang telah ada sebelumnya. Sebagai contoh, paku kecil temuan Levi Strauss untuk dipasang di ujung-ujung saku celana jeans, misalnya, yang kemudian dianugerahi hak paten di Amerika Serikat tahun 1873, mengandung solusi teknis terhadap persoalan mudah lepas/sobeknya jahitan saku celana berbahan denim ketika itu, mengingat pemakaian luar ruangan dengan intensitas yang cukup tinggi. Invensi paten dapat berupa produk ataupun proses. Contohnya pembakaran pada mesin kendaraan bermotor yang bertujuan untuk menghasilkan emisi gas buang yang lebih ramah lingkungan. Baik metode dan proses bagaimana pembakaran tersebut dilakukan, dan mesin yang menerapkan metode dan proses pembakaran itu, keduanya dapat dipatenkan masing-masing sebagai paten proses dan paten produk.

\section{PROSEDUR UNTUK} MEMPEROLEH HAK PATEN?

Syarat mengajukan permohonan hak paten HaKI karya intelektual benarbenar terbarukan. Belum ada yang pernah mengajukan sebelumnya. Adapun cara pengecekan apakah karya kita terbarukan atau tidak. kita dapat melakukan pengecekan dokumen paten di database DJHKI dan kantor paten di luar negeri. Misalnya, pengecekan terhadap jurnal ilmiah dan sejenisnya.

Jika karya kita belum bersifat terbarukan, proses selanjutnya adalah membuat proposal pengajuan paten. Proposal pengajuan paten meliputi judul invensi, latar belakang invensi, deskripsi singkat karya intelektual yang ditemukan dan gambar teknik. Gambar teknik yang disertai dengan 
uraian singkat. Kemudian dilengkapi dengan abstrak dan klaim. Rangkaian inilah yang kemudian disebut dengan penyusunan spesifikasi paten.

Spesifikasi paten sebagai syarat minimum yang harus disertakan. Adapun tiga syarat yang harus dipenuhi untuk memperoleh filing date, diantarannya memenuhi Spesifikasi paten, formulir permohonan dan biaya pendaftaran. Adapun persyaratan lain sebagai formalitas, dimana syarat ini dapat dilengkapi selama tiga bulan setelah menerima tanggal penerimaan. Berikut syarat permohonan yang perlu dipersiapkan.

$>$ Surat pernyataan hak

$>$ Surat perngalihan hak

$>$ Surat kuasa

$>$ Fotocopi KTP

- Fotokopi Akta pendirian badan hukum yang dilegaliris

$>$ Fotokopi NPWP badan hukum

Fotokopi KTP atas nama pemohon badan hukum untuk ditandatangai surat pernyataan dan surat kuasa.
Apabila syarat poin di atas sudah lengkap, inventor tinggal menunggu hasil dari DJHKI. Pengumuman akan dipublikasikan secara umum setelah 18 bulan dari hasil pengajuan. Pemohon paten selama menunggu pengumuman dimuat di berita resmi paten dan media resmi. Tujuannya untuk mengetahui hak kekayaan intelektual yang dipatenkan. Apabila masyarakat atau inventor luar merasa keberatan karena dianggap tidak memenuhi syarat untuk dipatenkan, dapat mengajukan secara tertulis kepada DJHKI.

Khusus inventor yang ditolak, diperbolehkan mengajukan banding ke Komisi Banding Paten. Nantinya, akan berlanjut ke Pengadilan Niaga dan kasasi Mahkamah Agung. Apabila inventor pengajuan hak paten tetap ditolak, maka hasil hak kekayaan intelektual akan menjadi public domain. Sedangkan untuk yang memperoleh hak paten, akan meperoleh sertifikat hak paten dari DJHKI. 


\section{STUDI KASUS}

Sebagai salah satu upaya dalam mengembangkan program pembelajaran secara berkelanjutan, Institut Bank Indonesia (BINS) telah menciptakan sebuah tools/alat bantu pembelajaran yaitu economic leadership boardgame yang digunakan sebagai sarana dalam memahami konsep economic leadership.

Boardgame tersebut dirancang secara khusus sebagai alat untuk menggali ide inovasi, game changing, dan juga sharing terobosan yang telah dan akan dilakukan para peserta melalui sistem permainan interaktif (experiential learning). Proses permainan interaktif didasarkan pada pengalaman keseharian, sinergi, serta kolaborasi antar peserta dan fasilitator, guna menghasilkan pengalaman pembelajaran yang optimal.

Economic leadership boardgame pertama kali diluncurkan pada tanggal 30 November 2016. Boardgame ini telah digunakan pada beberapa program pembelajaran yang diselenggarakan oleh BINS, seperti Economic Leadership for Regional

Government

Leader dan Youth

Economic

Leadership Program. Economic

leadership boardgame mendapatkan animo yang baik dari peserta, mulai dari kalangan mahasiswa hingga para pemimpin daerah. Adalah suatu kebanggaan bagi BINS yang berhasil mempersembahkan sebuah alat bantu program pembelajaran yang aplikatif dan diapresiasi banyak pihak. Untuk itu, sebagai wujud penghargaan atas ide dan buah karya para pihak yang terlibat, yang telah dituangkan pada boardgame tersebut.

BINS berinisiatif untuk mendaftarkan ciptaan tersebut secara resmi kepada Direktorat Jenderal Kekayaan Intelektual pada bulan Agustus 2017. Pendaftaran ini merupakan upaya untuk mencegah adanya klaim dari pihak lain terhadap hasil karya intelektual dimaksud. Rangkaian proses pengajuan hak cipta tersebut telah dilakukan secara bertahap untuk memenuhi persyaratan yang diperlukan. BINS telah melalui 
proses yang cukup panjang hingga pada akhirnya pada bulan Februari 2018 BINS berhasil mendapatkan pengakuan sah terhadap hak cipta economic leadership boardgame.

Pada tanggal 8 Februari 2018, BINS akhirnya resmi memperoleh hak cipta atas economic leadership boardgame. Kesahihan hak cipta tersebut dibuktikan dengan adanya sertifikat yang diberikan oleh Direktorat Jenderal Kekayaan Intelektual kepada BINS. Hak cipta atas economic leadership boardgame dipegang oleh Institut Bank Indonesia dan berlaku selama lima puluh (50) tahun sejak ciptaan tersebut pertama kali diumumkan ke depan, BINS tetap berkomitmen untuk mengembangkan ide dan kreasi inovatif dalam rangka menciptakan alat bantu pembelajaran yang lebih beragam dan sesuai dengan perkembangan terkini.

\section{Sanksi Jika Melanggar Paten Milik Orang Lain}

Suatu penemuan teknologi, secanggih apapun, tetapi tidak dapat diproduksi dalam skala industri (karena harganya sangat mahal atau tidak ekonomis), maka tidak berhak atas paten. Penemuan tersebut merupakan penemuan yang tidak terduga sebelumnya (non obvious). Tentunya dalam Undang Undang selain diatur mengenai hak paten juga terdapat hukuman bagi mereka yang melakukan pelanggaran hak paten .

Sebagimana Sanksi Pelanggaran Hak Paten berdasarkan Undang Undang yang berlaku di Indonesia.

\section{Undang-undang No.14 Tahun 2001 tentang Paten (UUP).}

(Pasal 130). Barangsiapa dengan sengaja dan tanpa hak melanggar hak Pemegang Paten dengan melakukan salah satu tindakan sebagaimana dimaksud dalam Pasal 16 dipidana dengan pidana penjara paling lama 4 (empat) tahun dan/atau denda paling banyak $\mathrm{Rp}$ 500.000.000,00 (lima ratus juta rupiah).

(Pasal 131). Barangsiapa dengan sengaja dan tanpa hak melanggar hak Pemegang Paten Sederhana dengan melakukan salah satu tindakan sebagaimana dimaksud dalam Pasal 16 
dipidana dengan pidana penjara paling lama 2 (dua) tahun dan/atau denda paling banyak Rp 250.000.000,00 (dua ratus lima puluh juta rupiah).

(Pasal 132). Barangsiapa dengan sengaja tidak memenuhi kewajiban sebagaimana dimaksud dalam Pasal 25 ayat (3), Pasal 40, dan Pasal 41 dipidana dengan pidana penjara paling lama 2 (dua) tahun.

(Pasal 133). Tindak pidana sebagaimana dimaksud dalam Pasal 130, Pasal 131, dan Pasal 132 merupakan delik aduan.

(Pasal 134). Dalam hal terbukti adanya pelanggaran Paten, hakim dapat memerintahkan agar barangbarang hasil pelanggaran Paten tersebut disita oleh Negara untuk dimusnahkan.

\section{B. Inventor}

Pemilik karya intelektual disebut dengan istilah inventor. Inventor bisa dilakukan secara individu maupun kelompok. Inventor lebih mudah mendapatkan hak paten atas hasil penemuan karya intelektual mereka. Sedangkan untuk diluar inventor terlebih dahulu memperoleh pengalihan hak secara tertulis dari sang inventor.

Apabila pihak lain yang memperoleh pengalihan hak dari inventor akan memiliki hak paten Selama 20 tahun dari hari pertama tanggal penerimaan. Sisanya, setelah 20 tahun hak ekslusif tersebut akan menjadi public domain. Public domain diperuntukan untuk masyarakat umum, tentu saja tetap melakukan proses ijin pada pemegang hak paten.

Hak paten dalam HaKI berprinsip territorial. Prinsip territorial dalam hal ini hak paten hanya berlaku di negara inventor mengajukan permohonan paten dan diberi. Pengajuan dilakukan dengan mengirimkan surat permohonan ke Direktoral Jenderal Hak Kekayaan Intelektual (DJHKI). Apabila inventor memperoleh hak paten di Indonesia, misalnya, maka hak paten yang diperoleh tidak berlaku atau tidak memiliki hak paten di negara lain.

Kewajiban inventor yang memperoleh hak paten HaKI berhak membayar biaya tahunan. Biaya tersebut bagian 
dari biaya pemeliharaan paten sampai dengan tahun terakhir masa perlindungan. Hak paten akan hilang secara hukum apabila tidak dibayar selama tiga tahun berturut-turut. Besar biaya pemeliharaan hak paten di tetapkan oleh PNBP Penerimaan Negara Bukan Pajak di Kementerian hukum dan HAM.

\section{Pemegang Paten}

Orang yang menghasilkan suatu invensi, baik sendirian maupun beberapa orang bersama-sama, disebut dengan istilah inventor. Inventor inilah yang paling pertama berhak mendapatkan hak paten atas invensi yang dihasilkannya. Siapa pun di luar inventor yang ingin memiliki hak paten atas invensi tersebut harus terlebih dahulu memperoleh pengalihan hak secara tertulis dari sang inventor. Baik Inventor maupun pihak lain yang menerima pengalihan hak dari inventor merupakan pemilik Hak Paten (Patentee), yang memiliki hak eksklusif untuk melaksanakan invensi yang dipatenkan tersebut selama 20 tahun dihitung dari Tanggal
Penerimaan. Setelah 20 tahun tersebut, invensi yang dimaksud akan menjadi milik umum (public domain) dan dapat dimanfaatkan oleh siapapun tanpa perlu meminta izin dari si pemegang paten.

\section{Hal-Hal Yang Harus Dihindari Sebelum Permintaan Paten Di Ajukan}

Yang harus dihindari sebelum permintaan paten diajukan adalah pengungkapan atau mempublikasikan secara umum hasil penelitian atau penemuan dalam jangka waktu 6 (enam) bulan sebelum permintaan paten diajukan. Pengugkapan suatu hasil penelitian atau penemuan dapat terjadi dalam 3 cara:

a. Melalui penguraian teknik dengan tulisa yang dipublikasikan.

b. Melalui penguraian produk dan atau cara penggunanya di depan umum.

c. Melalui pameran produk, dapat berupa suatu pameran internasional atau nasional di Indonesia atau di luar negeri 
yang resmi atau diakui sebagai resmi.

\section{E. Penjelesan Hasil Penenlitian}

Melalui penguraian teknik dengan tulisan yang dipublikasikan dapat melakukan penelususran (searching) informasi paten di beberapa website, antara lain: Melakukan analisa, dan men-cheek apakah ada ciri khusus dari invensi yang akan diajukan untuk mendapat perlindungan hak paten dibandingkan dengan invensi terdahulu, yang masih berlaku hak patennya. Economic leadership boardgame pertama kali diluncurkan pada tanggal 30 November 2016. Boardgame ini telah digunakan pada beberapa program pembelajaran yang diselenggarakan oleh BINS, seperti Economic Leadership for Regional Government Leader dan Youth Economic Leadership Program. Economic leadership boardgame mendapatkan animo yang baik dari peserta, mulai dari kalangan mahasiswa hingga para pemimpin daerah. Adalah suatu kebanggaan bagi BINS yang berhasil mempersembahkan sebuah alat bantu program pembelajaran yang aplikatif dan diapresiasi banyak pihak. Untuk itu, sebagai wujud penghargaan atas ide dan buah karya para pihak yang terlibat, yang telah dituangkan pada boardgame tersebut.

\section{B. CONCLUSION}

Pada intinya HKI adalah hak untuk menikmati secara ekonomis hasil dari suatu kreativitas intelektual. Objek yang diatur dalam HKI adalah karya-karya yang timbul atau lahir karena kemampuan intelektual manusia sebagimana ciri ciri masyarakat hukum adat. Adapun syarat-syarat dapat dibuatnya Hak Paten.Syarat agar bisa mendapatkan hak paten ada tiga yaitu penemuan tersebut merupakan penemuan baru. Yang kedua, penemuan tersebut diproduksi dalam skala massal atau industrial. Suatu penemuan teknologi, secanggih apapun, tetapi tidak dapat diproduksi dalam skala industri (karena harganya sangat mahal atau tidak ekonomis), maka tidak berhak atas paten. Yang ketiga, penemuan 
tersebut merupakan penemuan yang tidak terduga sebelumnya (non obvious). Tentunya dalam Undang Undang selain diatur mengenai hak paten juga terdapat hukuman bagi mereka yang melakukan pelanggaran hak paten.

\section{ACKNOWLEDGEMENT}

University Of Indonesia

University Of Mitra Indonesia

Telkom University

University Of Mellbourne

Saitama University

\section{REFERENCE (Based ISO 690 )}

[1] A. S. Putra And O. M. Febriani, "Knowledge Management Online Application In Pdam Lampung Province," In Prosiding International Conference On Information Technology And Business (Icitb), 2018, Pp. 181187.
A. S. Putra, O. M. Febriani, And
B. Bachry, "Implementasi

Genetic Fuzzy System Untuk Mengidentifikasi Hasil Curian Kendaraan Bermotor Di Polda Lampung," J. Sist. Inf. Dan Manaj. Basis Data, Vol. 1, No. 1, Pp. 21-30, 2018.

[3] O. M. Febriani And A. S. Putra, "Sistem Informasi Monitoring Inventori Barang Pada Balai Riset Standardisasi Industri Bandar Lampung," J. Inform., Vol. 13, No. 1, Pp. 90-98, 2014.

[4] Putra, Arie Setya. "2018 Artikel Struktur Data, Audit Dan Jaringan Komputer." (2018).

[5] Putra, A. S. (2018, July 17). Paperplain Fundamental Create Application With Borland Delphi 7.0 University Of Mitra Indonesia. Retrieved From Osf.Io/Pbrn9.

\section{E. REFERENCE (Based APA)}

Putra, A. S., Aryanti, D. R., \& Hartati, I. (2018, November). Metode SAW (Simple Additive Weighting) sebagai Sistem Pendukung Keputusan Guru Berprestasi (Studi Kasus: SMK Global 
Surya). In Prosiding Seminar Nasional

Darmajaya (Vol. 1, No. 1, pp. 85-97).

Sari, D. P., Febriani, O. M., \& Putra, A. S. (2018, November). Perancangan Sistem Informasi SDM Berprestasi pada SD Global Surya. In Prosiding Seminar Nasional Darmajaya (Vol. 1, No. 1, pp. 289-294).

Putra, A. S. (2018). Paperplain: Execution Fundamental Create Application With Borland Delphi 7.0 University Of Mitra Indonesia.

Putra, A. S., Sukri, H., \& Zuhri, K. Sistem Monitoring Realtime Jaringan Irigasi Desa (JIDES) Dengan Konsep Jaringan Sensor Nirkabel. IJEIS (Indonesian Journal of Electronics and Instrumentation Systems), 8(2), 221232.

Darmawan, A., Yuliawati, D., Marcella, O., \& Firmandala, R. (2016). Sistem Absensi dan Pelaporan Berbasis Fingerprint dan SMS Gateway. EXPLORE, 7(1).
Febriani, O. M., Wahyuni, T., \& Yusuf, S. (2017). DESIGN OF WEBSITE-BASED INFORMATION SYSTEM FOR EDOCUMENT ADMINISTRASI IN THE COMMUNITY SERVICE UNIT (A Case Study at Rajabasa District). INTERNATIONAL JOURNAL OF COMPUTERS \& TECHNOLOGY, 16(7), 7010-7020.

Febriani, O. M., \& Wahyuni, T. (2017, October). PERANCANGAN SISTEM E-DOCUMENT ADMINISTRASI LOGBOOK PENELITIAN PADA UNIT LAYANAN DI BANDAR LAMPUNG. In Prosiding Seminar Nasional Darmajaya (Vol. 1, No. 1, pp. 187-194).

Febriani, O. M., \& Permadi, A. B. (2017). Implementasi Sistem Aplikasi Data Bimbingan dan Pelanggaran Siswa pada Sekolah Menengah Atas di Lampung Tengah dengan Metode Analisis dan Desain Sistem Terdistribusi (SSAD). EXPERT, 7(1).

Febriani, O. M., \& Ambarwati, L. (2015). PERANCANGAN APLIKASI 
PENGOLAHAN DATA

PENJUALAN UKM KELANTING

KHAS TELO DESA SIDOHARJO

KECAMATAN JATI AGUNG

KABUPATEN LAMPUNG

SELATAN. Jurnal Teknologi

Informasi dan Bisnis Pengabdian

Masyarakat Darmajaya, 1(1), 77-95.

Febriani, O. M. (2015). Rancang

Bangun Aplikasi E-

commercemenggunakan Freewebstore

pada UKM Kelanting di Desa

Sidoharjo Lampung Selatan. Prosiding

Sembistek 2014, 1(02), 446-458. 